\title{
Comparative study on the thermal environmental responses of indigenous bamboo and modern brick houses in hot-humid climate of Malaysia
}

\begin{abstract}
Vernacular houses using indigenous building materials have shown to be a good strategy for sustainable energy consumption without compensating the occupant's indoor thermal comfort. Bamboo has been identified as the most used building material for vernacular houses in South-East Asia region. However, very little investigation has been conducted to study the passive performance of a bamboo house in maintaining indoor thermal comfort. This study compares the indoor microclimate conditions using thermal comfort Predicted Mean Vote and Predicted Percentage of Dissatisfied models (PMV-PPD) developed by American Society Heating, Refrigerating and Air-conditioning Engineers (ASHRAE) between indigenous bamboo house (H1) and modern brick house (H2) at a village located in the Ulu Gombak Forest Reserve, Selangor. Observations on environmental factors and predicted thermal comfort satisfaction level between day and night times were also taken into consideration. The findings suggest that the use of bamboo plus other vernacular house design features such as raising a house on stilts, located on hilly site and providing air permeability in $\mathrm{H} 1$ can lead to a thermally comfortable indoor environment, particularly during night time.
\end{abstract}

Keyword: Passive cooling; Indigenous bamboo house; Concrete house; PMV-PPD; outdoor and indoor temperature time lag; Thermal comfort 